\title{
ROLE OF ICT IN THE PROCESS OF E-MEDIA
}

\author{
M. J. Hedau \\ Department of Electronics, \\ Shri Shivaji Science College, Nagpur, India. \\ E-mail:- maheshhedau1@gmail.com
}

\begin{abstract}
:
The present paper describes the how ICT is useful in the process of Teaching and Learning. ICT enables selfpaced learning through various tools such as assignment, computer etc as a result of this the teaching learning enterprise has become more productive and meaningful. ICT helps facilitate the transaction between producers and users by keeping the students updated and enhancing teachers capacity and ability fostering a live contact between the teacher and the student through e-mail, chalk session, e-learning, web-based learning including internet, intranet, extranet, CD-ROM, TV audio-videotape. EDUSAT technology has become very powerful media for interactive participation of experts and learners and it reaches the unreachable. Emerging learning Technology (ELT) of bogging, Integrated Learning Â Modules, a pod cast, Wikis, Enhancement of Browsers, e-learning, M-learning, U-learning have started making rapid strides in teaching learning processes.
\end{abstract}

Keywords: Web Browsers, Technology enhanced learning, Self- paced learning, Instructional software.

\section{INTRODUCTION:}

Information and communication technology (ICT) that has changed many aspects in day to day life for ex in the fields such as medicine, tourism, travel, business, law, banking, engineering and architecture. The impact of ICT across the past two or three decades has been massive.

In the field of education to implement the ICT facility the following factors are to be considered:-

1. Funding to support the purchase of the technology

2. A lack of training among teaching faculty

3. A lack of motivation and need among teachers to adopt ICT as teaching tools

UGC \& NAAC encouraged to adopt ICTs into classrooms and learning process.

The Internet and WWW as a tools for information access and communication. ICTs in education and contemporary trends suggest we will soon see large scale changes in the way education is planned and delivered as a consequence of the opportunities and affordances of ICT.

These have included a growing need to explore efficiencies in terms of program delivery, the opportunities for flexible delivery provided by ICTs; the capacity of technology to provide support for customized educational programs to meet the needs of individual learners and the growing use of the Internet and WWW as tools for information access and communication. The factors and many others are bringing strong forces to bear on the adoption of ICTs in education and contemporary trends suggest we

will soon see large scale changes in the way education is planned and delivered as a consequence of the opportunities and affordances of ICT. This paper seeks to explore the likely changes we will see in education as ICT acts as a powerful agent to change many of the educational practices to which we have become accustomed. In particular, the paper will explore the impact both current and emerging information and communication technologies will be likely to have in coming years on what is learned, when and where learning will take place and how the learning will occur

\section{THE IMPACT OF ICT:}

The impact of ICT on what is learned Conventional teaching has content. For many years course have been written around textbooks. Teachers have taught through lectures and presentations interspersed with tutorials and 
learning activities designed by BOS of University for affiliated colleges and autonomous colleges designed their own syllabus.

Existing settings are now favoring curricula that promote skill and performance. Curricula are starting to emphasize capabilities and to be concerned more with how the information will be used than with what the information is. a. skill and performance-based curricula

The moves to skill and performance-based curricula are well supported and encouraged by emerging instructional technology of information sources;

1. Access to a variety of information forms and types ·

2. Access information access and inquiry;

3. Learning environments centered on problemcentered and inquiry-based activities; relevant information in order to engage with it or to solve a problem arising from it". The drive to promote such developments stems from general moves among institutions to ensure their graduates demonstrate not only skills and knowledge in their subject domains but also general attributes and generic skills. Traditionally generic skills have involved such capabilities as an ability to reason formally, to solve problems, to communicate effectively, to be able to negotiate outcomes, to manage time, project management, and collaboration and teamwork skills. The growing use of ICTs as tools of every day life have seen the pool of generic skills expanded in recent years to include information literacy and it is highly probable that future developments and technology applications will see this set of skills growing even more.

Existing ICTs are able to provide strong supportTHE IMPACT OF ICT ON HOW STUDENTS for all these requirements and there are now manyLEARN:

outstanding examples of world class settings for Technology is influencing and supporting competency and performance-based curricula thatwhat is being learned in colleges and universities, make sound use of the affordances of theseso too is it supporting changes to the way technologies. For many years, teachers wishing tostudents are learning. Moves from theoretical adopt such curricula have been limited by theirconcept to skilled based concept technologyresources and tools but with the proliferation andfacilitated approaches, and now encourage widespread availability of contemporary ICTs, manystudents to take responsibility for their own restrictions and weaknesses of the past have beenlearning .In the past students have become very removed. And new technologies will continue to drivecomfortable to learning through trans missive these forms of learning further. As students andmodes. Students have been trained to let others teachers gain access to higher bandwidths, morepresent to them the information that forms the direct forms of communication and access to sharablecurriculum.

resources, the capability to support these quality The growing use of ICT as an

learning settings will continue to grow.

\section{INFORMATION LITERACY:}

Another way in which emerging ICTs are impacting on the content of education curricula stems from the ways in which ICTs are dominating so much of contemporary life and work. Already there has emerged a need for educational institutions to ensure that graduates are able to display appropriate levels of information literacy, "the capacity to identify and issue and then to identify, locate and evaluate instructional medium is changing and will likely continue to change many of the strategies employed by both teachers and students in the learning process.

The following sections describe particular forms of learning that are gaining prominence in universities and schools worldwide.

A. Student-centered learning Technology has the capacity to promote and encourage the transformation of education from a very teacher directed enterprise to one which supports more 
student-centered models. Evidence of this today is manifested in: .

The proliferation of capability, competency and outcomes focused curricula - Moves towards problem-based learning increased use of the Web as an information source, Internet users are able to choose the experts from whom they will learn The use of ICT in educational settings, by itself acts as a catalyst for change in this domain. ICTs by their very nature are tools that encourage and support independent learning. Students using ICTs for learning purposes become immersed in the process of learning and as more and more students use computers as information sources and cognitive tools the influence of the technology on supporting how students learn will continue to increase.

\section{B. Supporting knowledge construction -}

The emergence of ICTs as learning technologies has coincided with a growing awareness and recognition of alternative theories for learning. The theories of learning that hold the greatest sway today are those based on constructivist principles These principles posit that learning is achieved by the active construction of knowledge supported by various perspectives within meaningful contexts. In constructivist theories, social interactions are seen to play a critical role in the processes of learning and cognition. In the past, the conventional process of teaching has revolved around teachers planning and leading students through a series of instructional sequences to achieve a desired learning outcome.

Typically these forms of teaching have revolved around the planned transmission of a body of knowledge followed by some forms of interaction with the content as a means to consolidate the knowledge acquisition. Contemporary learning theory is based on the notion that learning is an active process of constructing knowledge rather than acquiring knowledge and that instruction is the process by which this knowledge construction is supported rather than a process of knowledge transmission The strengths of constructivism lie in its emphasis on learning as a process of personal understanding and the development of meaning in ways which are active and interpretative. mentioned previously, any use of ICT in learning can act to support various aspects of knowledge construction and as more and more students employ ICTs in their learning processes, the more pronounced the impact of this will become.

\section{THE IMPACT OF ICT ON WHEN AND WHERE STUDENTS LEARN:}

In the past educational institutions have provided little choice for students in terms of the method and manner in which programs have been delivered. Students have typically been forced to accept what has been delivered and institutions have tended to be quite staid and traditional in terms of the delivery of their programs. ICT applications provide many options and choices and many institutions are now creating competitive edges for themselves through the choices they are offering students. These choices extend from when students can choose to learn to where they learn

a. any place learning The concept of flexibility in the delivery place of educational programs is not new.

Educational institutions have been offering programs at a distance for many years and there has been a vast amount of research and development associated with establishing effective practices and procedures in off-campus teaching and learning. Use of the technology, however, has extended the scope of this activity and whereas previously off-campus delivery was an option for students who were unable to attend campuses, today, many more students are able to make this choice through technology-facilitated learning settings. The scope and extent of this activity is demonstrated in some of the examples below. In many instances traditional classroom learning has given way to learning in work-based settings with students able to access courses and 
programs from their workplace. The advantages of education and training at the point of need relate not only to convenience but include cost savings associated with travel and time away from work, and also situation and application of the learning activities within relevant and meaningful contexts. - The communications capabilities of modern technologies provide opportunities for many learners to enroll in courses offered by external institutions rather than those situated locally. These opportunities provide such advantages as extended course offerings and eclectic class cohorts comprised of students of differing backgrounds, cultures and perspectives. - The freedoms of choice provided by programs that can be accessed at any place are also supporting the delivery of programs with units and courses from a variety of institutions, There are now countless ways for students completing undergraduate degrees for example, to study units for a single degree, through a number of different institutions, an activity that provides considerable diversity and choice for students in the programs they complete.

b. anytime learning In concert with geographical flexibility, technology-facilitated educational programs also remove many of the temporal constraints that face learners with special needs

Students are starting to appreciate the capability to undertake education anywhere, anytime and anyplace. This flexibility has heightened the availability of just-in-time learning and provided learning opportunities for many more learners who previously were constrained by other commitments . Through online technologies learning has become an activity that is no longer set within programmed schedules and slots. Learners are free to participate in learning activities when time permits and these freedoms have greatly increased the opportunities for many students to participate in formal programs. The wide variety of technologies that support learning are able to provide asynchronous supports for learning so that the need for real-time participation can be avoided while the advantages of communication and collaboration with other learners is retained. - As well as learning at anytime, teachers are also finding the capabilities of teaching at any time to be opportunistic and able to be used to advantage. Mobile technologies and seamless communications technologies support $24 \times 7$ teaching and learning. Choosing how much time will be used within the $24 \times 7$ envelope and what periods of time are challenges that will face the educators of the future The continued and increased use of ICTs in education in years to come, will serve to increase the temporal and geographical opportunities that are currently experienced. Advancements in learning opportunities tend to be held back by the ICT capabilities of the lowest common denominator, namely the students with the least access to ICT. As ICT access increases among students so too will these opportunities. Emerging Issues A number of other issues have emerged from the uptake of technology whose impacts have yet to be fully explored. These include changes to the makeup of the teacher pool, changes to the profile of who are the learners in our courses and paramount in all of this, changes in the costing and economics of course delivery.

a. expanding the pool of teachers In the past, the role of teacher in an educational institution was a role given to only highly qualified people. With technology-facilitated learning, there are now opportunities to extend the teaching pool beyond this specialist set to include many more people. The changing role of the teacher has seen increased opportunities for others to participate in the process including workplace trainers, mentors, specialists from the workplace and others. Through the affordances and capabilities of technology, today we have a much-expanded pool of teachers with varying roles able to provide support for learners in a variety of flexible settings. This trend seems set to 
continue and to grow with new ICT developments and applications. And within this changed pool of teachers will come changed responsibilities and skill sets for future teaching involving high levels of ICT and the need for more facilitative than didactic teaching roles (eg. Littlejohn et al., 2002).

b. expanding the pool of students In the past, education has been a privilege and an opportunity that often was unavailable to many students whose situation did not fit the mainstream. Through the flexibilities provided by technology, many students who previously were unable to participate in educational activities are now finding opportunities to do so. The pool of students is changing and will continue to change as more and more people who have a need for education and training are able to take advantage of the increased opportunities. Interesting opportunities are now being observed among, for example, school students studying university courses to overcome limitations in their school programs and workers undertaking courses from their desktops.

c. the cost of education Traditional thinking has always been that technologyfacilitated learning would provide economies and efficiencies that would see significant reductions in the costs associated with the delivery of educational programs. The costs would come from the ability to create courses with fixed establishment costs, for example technologybased courses, and for which there would be savings in delivery through large scale uptake. We have already seen a number of virtual universities built around technology delivery alone (eg. Jones International University, www. jiu.edu). The reality is that few institutions have been able to realize these aims for economy. There appear to have been many underestimated costs in such areas as course development and course delivery. The costs associated with the development of high quality technology-facilitated learning materials are quite high. It has found to be more than a matter of repackaging existing materials and large-scale reengineering has been found to be necessary with large scale costs. Likewise, costs associated with delivery have not been found to diminish as expected. The main reason for this has been the need to maintain a relatively stable student to staff ratio and the expectation of students that they will have access to teachers in their courses and programs. Compared to traditional forms of off-campus learning, technology-facilitated learning has proven to be quite expensive in all areas of consideration, infrastructure, course development and course delivery. We may have to brace ourselves for the advantages and affordances which will improve the quality of education in the near future to also increase components of the cost. Stakeholders and influences The ideas that have been discussed in this paper suggest that while ICTs may not have had a large impact to date, their use will grow to play a significant role in many aspects of the design, development and delivery of educational programs in the coming years. The various influences that have been discussed provide examples of an agent that has the capacity to influence education at all levels and hence to be an agent supporting and encouraging considerable change. When the future of education is considered in this way, it is interesting to speculate among the stakeholders, for whom the change will be the greatest. Table 1 lists the principal stakeholders and suggests how the various issues discussed in the paper might influence each. Clearly the stakeholders for whom technology would seem to proffer the most influence and change are the students. So while institutions are pondering how they will be influenced in years to come, whatever the outcomes, the beneficiaries of the activity and change will be the students. This would seem to be the outcome everyone would want to see.

\section{SUMMARY AND CONCLUSIONS:}

This paper has sought to explore the role of ICT in education as we progress into the $21 \mathrm{st}$ 
century. In particular the paper has argued that ICTs have impacted on educational practice in education to date in quite small ways but that the impact will grow considerably in years to come and that ICT will become a strong agent for change among many educational practices. Extrapolating current activities and practices, the continued use and development of ICTs within education will have a strong impact on: - What is learned; · How it is learned; - When and where learning takes place; - Who is learning and who is teaching. The upshot of all this activity is that we should see marked improvements in many areas of educational endeavor. Learning should become more relevant to stakeholders' needs, learning outcomes should become more deliberate and targeted, and learning opportunities should diversity in what is learned and who is learning. At the same time, quality of programs as measured by fitness for purpose should continue to grow as stakeholder groups find the offerings matched to their needs and expectations. To ensure that the opportunities and advantages are realized, it will be important as it is in every other walk of life to ensure that the educational research and development dollar is sustained so that education at large can learn from within and that experiences and activities in different institutions and sectors can inform and guide others without the continual need for reinvention of the wheel. Once again ICTs serve to provide the means for much of this activity to realize the potential it holds.

\section{REFERENCES:}

Guiding principles in Web-based instructional design. Education Media International, 35(2), $72-76$.

Collis, B. (2002). Information technologies for education and training. In Adelsberger, H., Collis, B, \&Pawlowski, J. (Eds.) Handbook on Technologies for Information and Training. Berlin: Springer Verlag.
Duffy, T., \& Cunningham, D. (1996). Constructivism: Implications for the design and delivery of instruction, Handbook of research for educational telecommunications and technology (pp. 170-198). New York: MacMillan.

Freeman, M. (1997). Flexibility in access, interactions and assessment: The case for web-based teaching programs. Australian Journal of Educational Technology, 13(1), 23-39.

Jonassen, D. \& Reeves, T. (1996). Learning with technology: Using computers as cognitive tools. In D. Jonassen (Ed.), Handbook of Research Educational on Educational Communications and Technology (pp 693-719). New York:

Macmillan. Kennedy, D. \& Mc Naught, C.(1997). Design elements for interactive multimedia. Australian Journal of Educational Technology, 13(1), 1-22.

Laffey J., Tupper, T. \& Musser, D. (1998) A computer-mediated support system for project-based learning. Educational Technology Research and Development, 46(1), 73-86.

Lebow, D. (1993). Constructivist values for instructional systems design: Five principles toward a new mindset. Educational Technology, Research and Development, 41(3), 4-16. Littlejohn, A., Suckling, C., Campbell, L. \&Mc Nicol, D. (2002). The amazingly patient tutor: students' interactions with an online carbohydrate chemistry course. British Journal of Educational Technology, 33(3), 313-321.

Mc Causland, H., Wache, D. \& Berk, M. (1999). Computer literacy; its implications and outcomes. A case study from the Flexible Learning Centre. University of South Australia. 
Moore, M. \& Kearsley, G. (1996). Distance Education: A Systems View. Belmont, CA: Wadsworth.

Oliver, R. \& Short, G. (1996). The Western Australian Telecentres Network: A model for enhancing access to education and training in rural areas. International Journal of Educational Telecommunications, 2(4), 311-328.

Oliver, R. (2000). Creating Meaningful Contexts for Learning in Web-based Settings. Proceedings of Open Learning 2000. (pp 53-62). Brisbane: Learning Network, Queensland.

Oliver, R. \& Towers, S. (2000). Benchmarking ICT literacy in tertiary learning settings. In R. Sims, M. O' Reilly \& S. Sawkins (Eds). Learning to choose: Choosing to learn. Proceedings of the 17th Annual ASCILITE Conference (pp 381-390). Lismore, NSW: Southern Cross University Press.

Soloway, E. \& Pryor, A. (1996). The next generation in human-computer interaction. Communications of the ACM, 39(4), 16-18. Starr, L. (2001). Same time this year. [on-line]. Available at http://www.educationworld.com/a_tech/tech075.shtml [Accessed July 2002].

Stephenson, J., Ed. (2001). Learner-managed learning- an emerging pedagogy for online learning. Teaching and Learning Online: Pedagogies for New Technologies. London, 